\title{
Robust control of a chemical reactor with uncertainties
}

\author{
Anna Vasičkaninová, Monika Bakošová \\ Institute of Information Engineering, Automation and Mathematics, \\ Faculty of Chemical and Food Technology, Slovak University of Technology, \\ Radlinského 9, 81237 Bratislava, Slovakia \\ anna.vasickaninova@stuba.sk
}

\begin{abstract}
This work deals with the design and the application of a robust control to a chemical reactor. The reactor is exothermic one. There are two parameters with only approximately known values in the reactor. These parameters are the reaction enthalpies. Because of the presence of uncertainty, the robust output feedback is designed. Two robust controllers are designed, the first one is based on the small gain theorem and the second one uses the $H_{2} / H_{\infty}$ control techniques. The presented experimental results confirm applicability of mentioned approaches to safe control of nonlinear processes.
\end{abstract}

Keywords: exothermic chemical reactor, robust control, small gain theorem, $H_{2} / H_{\infty}$ control

\section{Introduction}

In this paper the small gain theorem and the $H_{2} / H_{\infty}$ control techniques are applied to control of a chemical reactor.

It is well known that the control of chemical reactors represents very complex problem (Luyben 2007; Molnár et al. 2002). Continuous stirred tank reactors (CSTRs) are often used plants in chemical industry and especially exothermic CSTRs are very interesting systems from the control viewpoint (Bequette 1991). The dynamic characteristics may exhibit e.g. a varying sign of the gain in various operating points, the time delay or the non-minimum phase behaviour. Various types of disturbances also affect operation of chemical reactors, operation of chemical reactors is corrupted by different uncertainties. Some of them arise from varying or not exactly known parameters, as e.g. reaction rate constants, reaction enthalpies or heat transfer coefficients (Antonelli and Astolfi 2003). All these problems can cause poor control response or even instability of classical closed-loop control systems.

Effective control of CSTRs requires application of some of advanced methods, as e. g. robust control (Gerhard et al. 2004; Tlacuahuac et al. 2005). Robust control has grown as one of the most important areas in the modern control design since works by (Doyle 1981; Zames 1983) and many others.

The classical small-gain theorem (Green and Limebeer 1994) is an important tool for analyzing the input-output stability of feedback systems and the tool for robust controller design for systems with unstructured uncertainty (Nešić and Liberzon 2005; Karafyllis and Zhong-Ping 2007). Some nonlinear versions of the classical small-gain theorem are derived for input-output stability of nonlinear feedback systems. The notion of input-to-state stability (ISS) was originally introduced by Sontag (Sontag 1989). Following this, a nonlinear, generalized small-gain theorem was developed (Jiang et al. 1996). Stability of interconnections of ISS systems has been studied by many authors (Laila and Nešić, 2003; Chaves 2005; Teel 2005; Angeli and Astolfi 2007; Ito 2008).

$H_{2}$ and $H_{\infty}$ control theories have been active areas of research for the years and have been successfully introduced to many engineering applications. $\mathrm{H}_{2}$ - optimization finds a controller which minimizes the $\mathrm{H}_{2}$ norm of the closed-loop transfer function and internally stabilizes the system. The closed-loop transfer function to be minimized is located between the external signal and the control error signal (Kučera 2008). The polynomial solution of the standard $\mathrm{H}_{2}$ problem is proposed e.g. in (Henrion et al. 2005; Kučera 2007; Yang et al. 2007). There exist various solutions also of the standard $H_{\infty}$ problem. While the $H_{2}$ norm of a signal is the mean energy with respect to the frequency, the $H_{\infty}$ norm is the maximum energy with respect to the frequency. If there are uncertainties in the system model, some quantity combining the $H_{2}$ norm and the $H_{\infty}$ norm can be a desirable measure of a system's robust performance. Thus the mixed $H_{2} / H_{\infty}$ performance criterion provides an interesting measure for the controller evaluation. The theoretic motivation for the mixed $\mathrm{H}_{2} / \mathrm{H}_{\infty}$ control problem has been discussed in ((Doyle 1984; Kwakernaak 2002; Scherer 2006).

In the presented paper, the small gain theorem and the mixed $\mathrm{H}_{2} / \mathrm{H}_{\infty}$ control theory with poleplacement are applied to robust controller design. 


\section{Small gain theorem}

Suppose that the transfer function of an uncertain continuous-time system with additive unstructured uncertainty has the form

$$
G(s)=G_{n}(s)+G_{\Delta a}(s)=G_{n}(s)+W_{a}(s) \Delta_{a}(s)
$$

where $G_{n}(s)$ is the nominal model, $W_{a}(s)$ is the weight function and $\Delta_{a}(s)$ is a category of uncertainties that satisfies the condition $\left|\Delta_{a}(j \omega)\right| \leq 1$ for $\forall \omega$.

The task is to find a robust controller for control of the system (1). The design method is based on the small gain theorem (Green and Limebeer 1994; Veselý and Harsanyi 2007) and uses the fact that if a feedback loop consists of a stable systems and the loop-gain product is less than unity, then the feedback loop is internally stable. The other basis for the design is a fixed point theorem known as the contraction mapping theorem (Khalil 1996).

According to the small gain theorem, following conditions have to be satisfied: the controller with the transfer function $C(s)$ stabilizes the nominal model and for the open-loop transfer function $L(s)$, the condition given in (2) also holds.

$$
L(s)=G(s) C(s),|L(j \omega)|<1
$$

The family of the controlled system transfer functions $G(s)$ creates a set, in which $G_{n}(s)$ is the transfer function of the nominal system and $G_{k}(s)$ is a transfer function from the set $G(s)$, which differs from $G_{n}(s)$. Then, the value $l_{a}(\omega)$ can be calculated as the maximal value of modules as it is shown in (3)

$$
\begin{gathered}
l_{a}(s)=\max \left|G_{k}(j \omega)-G_{n}(j \omega)\right|, \\
\omega \in(0, \infty), k=1,2 \ldots
\end{gathered}
$$

The characteristic equation of the closed loop with the uncertain controlled system is

$$
1+G(s) C(s)=0
$$

and after the substitution (1) into (4), we obtain

$$
[1+G(s) C(s)]\left[1+T_{0}(s) \frac{G_{\Delta a}(s)}{G_{n}(s)}\right]=0
$$

where $T_{0}(s)$ is the closed-loop transfer function with the nominal model and has the form

$$
T_{0}(s)=\frac{G_{n}(s) C(s)}{1+G_{n}(s) C(s)}
$$

The closed loop must be stable. The small gain theorem requires satisfying also the second condition. It follows from (5) that for the second term in (5) the following condition holds

$$
\left[1+T_{0}(s) \frac{G_{\Delta a}(s)}{G_{n}(s)}\right]=0
$$

Then after the substitution $s=j \omega$ we obtain

$$
\left|T_{0}(j \omega) \frac{G_{\Delta a}(j \omega)}{G_{n}(\omega)}\right|<1, \forall \omega \in(0, \infty)
$$

The conditions $\left|\Delta_{a}(j \omega)\right|=1$ and $\left|W_{a}(j \omega)\right|=l_{a}(\omega)$ represent the worst cases and so, it is possible to rewritten (8) to the form

$$
\left|T_{0}(j \omega)\right|<\frac{\left|G_{n}(j \omega)\right|}{l_{a}(\omega)}
$$

Robust controller design is then based on finding parameters of the transfer function $T_{0}(s)$, the choice of the structure of the robust controller and calculation of the controller parameters.

\section{Mixed $\mathrm{H}_{2} / \mathrm{H}_{\infty}$ control synthesis}

The role of $H_{\infty}$ is to minimize the disturbance effect on the system output whereas $H_{2}$ is used to improve the transients against random disturbances.

Consider the plant model with the feedback as shown in Figure 1 (Bosgra and Kwakernaak 2000). The signal $w$ represents the external input, $z$ is the error of control, $u$ is the manipulated variable vector, and $y$ is the measured output. The block $G$ is the generalised controlled process, and $C$ is the compensator

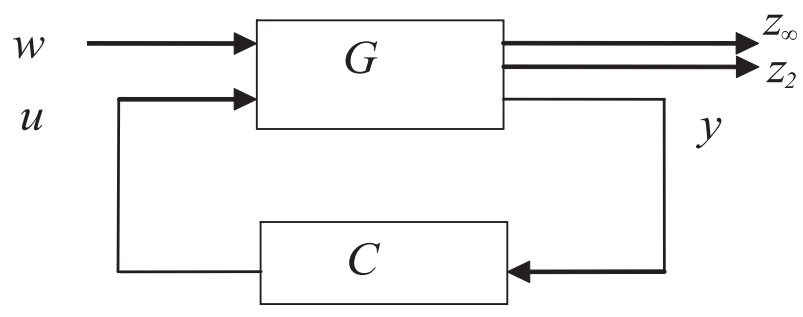

Fig. 1. Standard control configuration.

The loop gain has a direct effect on important closed-loop transfer functions which determine the norm, such as the sensitivity $S$ and the complementary sensitivity $T$. The sensitivity and the complementary sensitivity functions are given by

$$
\begin{gathered}
S=(I+G C)^{-1} \\
T=(I+G C)^{-1} G C
\end{gathered}
$$

The $H_{2} / H_{\infty}$ problem represents finding a controller $C$ which minimizes the mixed $H_{2} / H_{\infty}$ criterion

$$
\left.\mu|| T_{\infty}||\right|_{\infty} ^{2}+\eta|| T_{2}||_{2}^{2}
$$

where, $T_{\infty}(s)$ and $T_{2}(s)$ denote the closed-loop transfer functions from $w$ to $z_{\infty}$ and $z_{2}$, respectively, $\mu$ and $\eta$ are scalar factors.

Assume $G$ has realization

$$
\begin{gathered}
\dot{x}=A x+B_{1} w+B_{2} u \\
z_{\infty}=C_{\infty} x+D_{\infty 1} w+D_{\infty 2} u \\
z_{2}=C_{2} x+D_{21} w+D_{22} u \\
y=C_{y} x+D_{y 1} w+D_{y 2} u
\end{gathered}
$$


where $z_{\infty}$ is the output associated with the $H_{\infty}$ performance, $z_{2}$ is the output associated with the $\mathrm{H}_{2}$ performance (with the LQG aspects).

Let the closed-loop equations be

$$
\begin{gathered}
\dot{x}_{c l}=A_{c l} x_{c l}+B_{c l} w \\
z_{\infty}=C_{c l \infty} x_{c l}+D_{c l \infty} w \\
z_{2}=C_{c l 2} x_{c l}+D_{c l 2} w
\end{gathered}
$$

The closed-loop transfer functions $T_{\infty}(s)$ and $T_{2}(s)$ are

$$
\begin{aligned}
& T_{2}(s)=C_{c l 2}\left(s I-A_{\mathrm{cl}}\right)^{-1} B_{c l}+D_{c l 2} \\
& T_{\infty}(s)=C_{c l b o}\left(s I-A_{\mathrm{cl}}\right)^{-1} B_{c l}+D_{c l 00}
\end{aligned}
$$

\section{$H_{\infty}$ performance}

Lemma 1: The closed-loop random Mean Square (RMS) gain for $T_{\infty}(s)$ does not exceed $\gamma$ if and only if there exists a symmetric matrix such that (Chilali and Gahinet 1996; Scherer et al. 1997):

$$
\left(\begin{array}{l}
A_{c l} X_{\infty}+X_{\infty} A_{c l}^{T} B_{c l} X_{\infty} C_{c l \infty}^{T} \\
B_{c l \infty}^{T}-I D_{c l \infty}^{T} \\
C_{c l \infty} X_{\infty} D_{c l \infty}-\gamma^{2} I
\end{array}\right)<0, x_{\infty}>0
$$

\section{$\mathrm{H}_{2}$ performance}

Lemma 2: The closed-loop $H_{2}$-norm of $T_{2}(s)$, $\left\|T_{2}\right\|_{2}^{2}=\operatorname{tr}\left(C_{c l 2} x_{2} C_{c l 2}^{T}\right)$, does not exceed $v$ if and only $D_{c l 2}=0$ and there exist two symmetric matrices $X_{2}>0$ and $Q$ such that (Chilali and Gahinet 1996; Scherer et al. 1997):

$$
\begin{aligned}
& \left(\begin{array}{l}
A_{c l} X_{2}+X_{2} A_{c l}^{T} B_{c l} \\
B_{c l}^{T}-I
\end{array}\right)<0, \\
& \left(\begin{array}{l}
Q C_{c l} X_{2} \\
X_{2} C_{c l}^{T} X_{2}
\end{array}\right)>0, \operatorname{tr}(Q)<v_{2}
\end{aligned}
$$

The $H_{2}$ and the $H_{\infty}$-norm are objectives that mutually compete, therefore a controller is found by solving (10), restricted to the former LMIs constraints:

$\operatorname{minimize}|| W_{1} S||_{2}$ subject to ||$W_{2} T||_{\infty}<\gamma_{\infty}$

\section{Simulations and results}

Consider a continuous-time stirred tank reactor (CSTR) with the first order irreversible parallel exothermic reactions according to the scheme

$$
A \stackrel{k_{1}}{\longrightarrow} B, A \stackrel{k_{2}}{\longrightarrow} C,
$$

where $\mathrm{B}$ is the main product and $\mathrm{C}$ is the side product (Ingham et al. 1994; Vasičkaninová and Bakošová 2009; Vasičkaninová et al. 2011). The dynamic mathematical model of the reactor is obtained by mass balances of reactants, enthalpy balance of the reactant mixture and enthalpy balance of the coolant. Assuming ideal mixing in the reactor and the other usual simplifications, the simplified nonlinear dynamic mathematical model of the chemical reactor constitute four differential equations

$$
\frac{d c_{A}}{d t}=\frac{q}{V} c_{A v}-\frac{q}{V} c_{A}-k_{1} c_{A}-k_{2} c_{A}
$$

$$
\frac{d c_{B}}{d t}=\frac{q}{V} c_{B v}-\frac{q}{V} c_{B}+k_{l} c_{A}
$$

$$
\begin{array}{r}
\frac{d T}{d t}=\frac{q}{V} T_{v}-\frac{q}{V} T-\frac{A k}{V \hat{A} c_{p}}\left(T-T_{c}\right)-\frac{h_{1} k_{1}+h_{2} k_{2}}{A ́ c p} c_{A} \\
\frac{d T_{c}}{d t}=\frac{q_{c}}{V_{c}} T_{v c}-\frac{q_{c}}{V_{c}} T_{c}+\frac{A k}{V_{c} \hat{A}_{c} c_{p c}}\left(T-T_{c}\right)
\end{array}
$$

The reaction rate coefficients are the non-linear functions of the reaction temperature being defined by the Arrhenius relations

$$
k_{i}=k_{i 0} e^{-\frac{E i}{R T}}, i=1,2
$$

In (18) - (22), $c$ are concentrations, $T$ are temperatures, $V$ are volumes, $\rho$ are densities, $c_{p}$ are specific heat capacities, $q$ are volumetric flow rates, $h$ are reaction enthalpies, $A$ is the heat transfer area, $k_{i}$ is the heat transfer coefficient, $k_{i 0}$ is the pre-exponential factor, $E$ is the activation energy and $R$ is the universal gas constant. The subscript $c$ denotes the coolant, the subscript $v$ denotes the input and the superscript $s$ denotes the steady-state values in the main operating point. The values of constant parameters and steady-state inputs of the chemical reactor are summarized in Table 1. Model uncertainty of the over described reactor follows from the fact that there are two physical parameters in this reactor, the reaction enthalpies, which values are known within following intervals (Table 2). The nominal values of these parameters are mean values of theirs intervals.

The reactions in the described reactor are exothermic ones and the heat generated by the chemical reactions is removed by the coolant in the jacket of the tank. The measured output is the temperature of the reaction mixture $T$, the coolant flow rate $q_{c}$ is chosen as the control input.

The open-loop behaviour of the reactor was also studied using the data given in Table 1 and Table 2. Because of the presence of uncertainties, the reacting mixture temperatures obtained for the nominal model and also for 4 vertex systems are shown in Figure 2, $0-$ nominal system, $1-h_{1 \text { min }}$, $h_{2 \min }, 2-h_{1 \max }, h_{2 \max }, 3-h_{1 \max }, h_{2 \min }, 4-h_{1 \min }$, $h_{2 \max }$. 
Tab. 1. Constant parameters and steady-state inputs of the chemical reactor.

\begin{tabular}{|c|c|c|}
\hline Variable & Unit & Value \\
\hline$q$ & $\mathrm{~m}^{3} \min ^{-1}$ & 0.015 \\
\hline V & $\mathrm{m}^{3}$ & 0.23 \\
\hline$V_{c}$ & $\mathrm{~m}^{3}$ & 0.21 \\
\hline$\rho$ & $\mathrm{kg} \mathrm{m}^{-3}$ & 1020 \\
\hline$\rho_{c}$ & $\mathrm{~kg} \mathrm{~m}^{-3}$ & 998 \\
\hline$c_{p}$ & $\mathrm{~kJ} \mathrm{~kg}^{-1} \mathrm{~K}^{-1}$ & 4.02 \\
\hline$c_{p c}$ & $\mathrm{~kJ} \mathrm{~kg}^{-1} \mathrm{~K}^{-1}$ & 4.182 \\
\hline$A$ & $\mathrm{~m}^{2}$ & 1.51 \\
\hline$k$ & $\mathrm{~kJ} \mathrm{~m}^{-2} \min ^{-1} \mathrm{~K}^{-1}$ & 42.8 \\
\hline$k_{10}$ & $\min ^{-1}$ & $1.55 \times 10^{11}$ \\
\hline$k_{20}$ & $\min ^{-1}$ & $4.55 \times 10^{25}$ \\
\hline$E_{1} / R$ & $\mathrm{~K}$ & 9850 \\
\hline$E_{2} / R$ & $\mathrm{~K}$ & 22019 \\
\hline$c_{A v}$ & $\mathrm{kmol} \mathrm{m}^{-3}$ & 4.22 \\
\hline$c_{B v}$ & $\mathrm{kmol} \mathrm{m}^{-3}$ & 0 \\
\hline$c_{C v}$ & $\mathrm{kmol} \mathrm{m}^{-3}$ & 0 \\
\hline$T_{v}$ & $\mathrm{~K}$ & 328 \\
\hline$T_{v c}$ & K & 298 \\
\hline$q_{c}^{s}$ & $\mathrm{~m}^{3} \min ^{-1}$ & 0.004 \\
\hline$T^{3}$ & $\mathrm{~K}$ & 363.61 \\
\hline$T_{c}$ & K & 350.15 \\
\hline$c_{A}^{s}$ & $\mathrm{kmol} \mathrm{m}^{-3}$ & 0.4915 \\
\hline$c_{B}^{s}$ & $\mathrm{kmol} \mathrm{m}^{-3}$ & 2.0042 \\
\hline$c_{C}^{s}$ & $\mathrm{kmol} \mathrm{m}^{-3}$ & 1.7243 \\
\hline
\end{tabular}

Tab. 2. Uncertain parameters of the chemical reactor.

\begin{tabular}{ccc}
\hline Variable & Unit & Value \\
\hline$-h_{1 \min }$ & $\mathrm{kJ} \mathrm{kmol}^{-1}$ & $8.4 \times 10^{4}$ \\
$-h_{1 \max }$ & $\mathrm{kJ} \mathrm{kmol}^{-1}$ & $8.8 \times 10^{4}$ \\
$-h_{2 \min }$ & $\mathrm{kJ} \mathrm{kmol}^{-1}$ & $1.62 \times 10^{4}$ \\
$-h_{2 \max }$ & $\mathrm{kJ} \mathrm{kmol}^{-1}$ & $2.02 \times 10^{4}$ \\
\hline
\end{tabular}

\section{Robust controller design based on the small gain theorem}

A robust PID controller was designed for control of the reaction mixture temperature. The transfer functions for the nominal system and 4 vertex systems are found for the step change of the coolant flow rate $q_{c}$ from $0.004 \mathrm{~m}^{3} \mathrm{~min}^{-1}$ to $0.008 \mathrm{~m}^{3} \mathrm{~min}^{-1}$ :

$$
\begin{gathered}
G_{n}(s)=\frac{-1290}{85.184 s^{3}+58.08 s^{2}+13.2 s+1} \\
G_{1}(s)=\frac{-1580}{125 s^{3}+75 s^{2}+15 s+1} \\
G_{2}(s)=\frac{-1030}{216 s^{3}+108 s^{2}+18 s+1} \\
G_{3}(s)=\frac{-1400}{91.125 s^{3}+60.75 s^{2}+13.5 s+1} \\
G_{4}(s)=\frac{-1200}{103.82 s^{3}+66.27 s^{2}+14.1 s+1}
\end{gathered}
$$

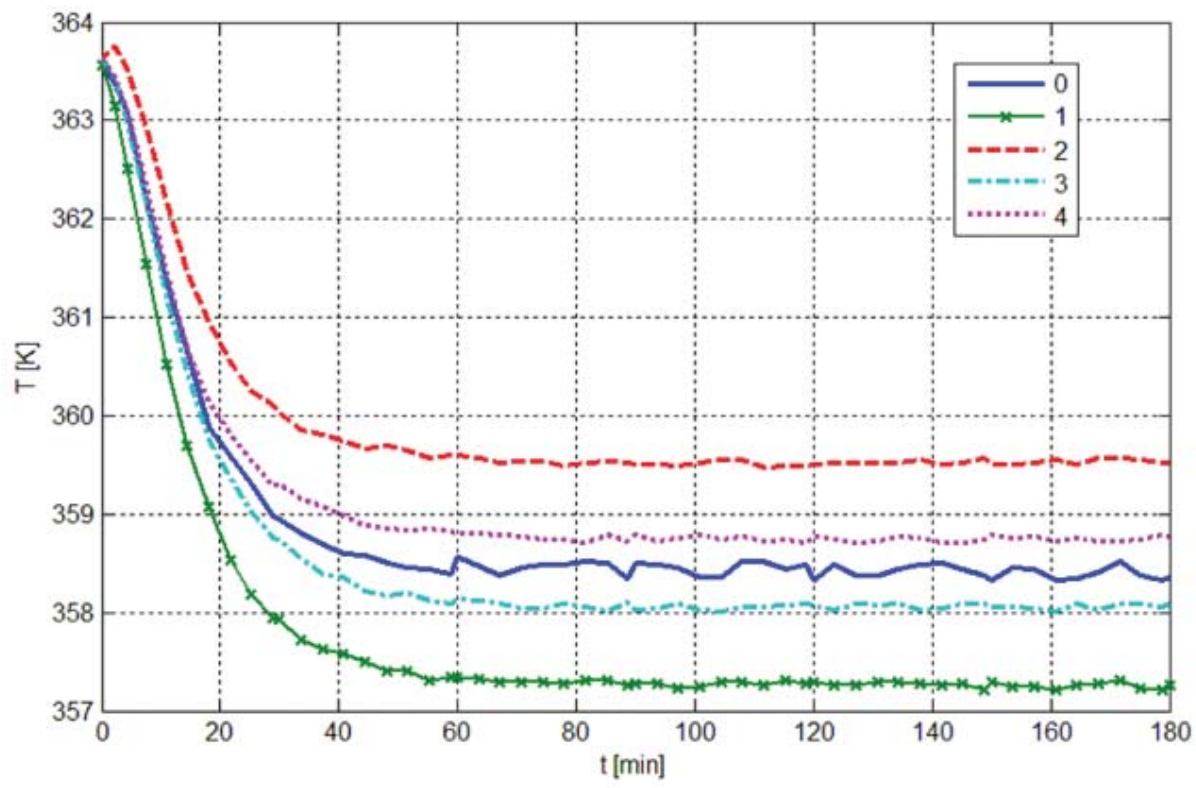

Fig. 2. Open-loop response of the CSTR - the reacting mixture temperature: 0 - nominal system, 1, 2, 3, 4-vertex systems. 
The transfer function $T_{0}(s)$ is in the form

$$
T_{0}(s)=\frac{G_{\text {numu }}(s)}{G_{\text {num }}(s)+D_{\text {nden }}(s) r s}
$$

The controller transfer function has the structure

$$
\begin{gathered}
C(s)=\frac{C_{\text {num }}(s)}{C_{\text {den }}(s)}= \\
=\frac{1}{r} \frac{c_{2} s^{2}+c_{1} s+c_{0}}{s}=P+\frac{I}{s}+D s
\end{gathered}
$$

The parameter $r$ is an optional parameter and the function $T_{0}(s)$ has to satisfy (9). The polynomial $D_{n \text { den }}(s)$ is optional, too, and the following equation has to be satisfied

$$
G_{n d e n}(s)=D_{n d e n}(s) C(s)
$$

Unknown parameters are $d_{1}=4.4, c_{2}=19.36, c_{1}=8.8$, $c_{0}=1$ and they are calculated from

$$
\begin{gathered}
85.184 s^{3}+58.08 s^{2}+13.2 s+1= \\
=\left(d_{1} s+1\right)\left(c_{2} s^{2}+c_{1} s+c_{0}\right)
\end{gathered}
$$

The transfer function $T_{0}(s)$ is affected by the choice of the parameter $r$ and has the form

$$
T_{0}(s)=\frac{1}{d_{1} r s^{2}+r s+1}
$$

The choice of $r$ depends on the control signals boundaries, too. In Figure 3 the reference trajectory and the reacting mixture temperature obtained using the PID controller with parameters $r=500$, $P=-1.76 \times 10^{-2}, I=-2.0 \times 10^{-3}, D=-3.87 \times 10^{-2}$ for the nominal model and also for 4 vertex systems are shown. Here, 0 is the nominal system and the vertex systems are the following combinations: $1-h_{1 \text { min }}$, $h_{2 \min }, 2-h_{1 \max }, h_{2 \max }, 3-h_{1 \max }, h_{2 \min }, 4-h_{1 \min }, h_{2 \max }$.

Figure 3 presents the set-point tracking and the disturbance rejection in the reactor. The disturbances were represented by the feed temperature changes of the reaction mixture. Following load disturbances were supposed: the feed temperature for the reaction mixture decreased by $5 \mathrm{~K}$ at $t=100 \mathrm{~min}$, increased by $3 \mathrm{~K}$ at $t=300 \mathrm{~min}$, decreased by $6 \mathrm{~K}$ at $t=500 \mathrm{~min}$.

Figure 4 presents the control signal for the set-point tracking and the disturbance rejection.

\section{$\mathrm{H}_{2} / \mathrm{H}_{\infty}$ control}

The transfer function describing the nominal system was supposed for the controller order reduction in the form (33) with parameters: $K=-1266$, $T=7 \mathrm{~min}, n=2$. These parameters were used for the $H_{2} / H_{\infty}$-controller tuning.

$$
G(s)=\frac{K}{(T s+1)^{n}}
$$

The controller was found in the form

$$
C(s)=\frac{-0.2759 s^{2}-0.0903 s-0.0084}{s^{3}+3.9507 s^{2}+7.6899 s+0.1048}
$$

In Figure 5 the reference trajectory and the reacting mixture temperature obtained using $H_{2} / H_{\infty}$ controller for the nominal model and for 4 vertex systems are shown. The $H_{2} / H_{\infty}$ controller attenuates disturbances fast and the overshoots caused by disturbances are minimal. The trajectory of the controlled variable are almost identical for the

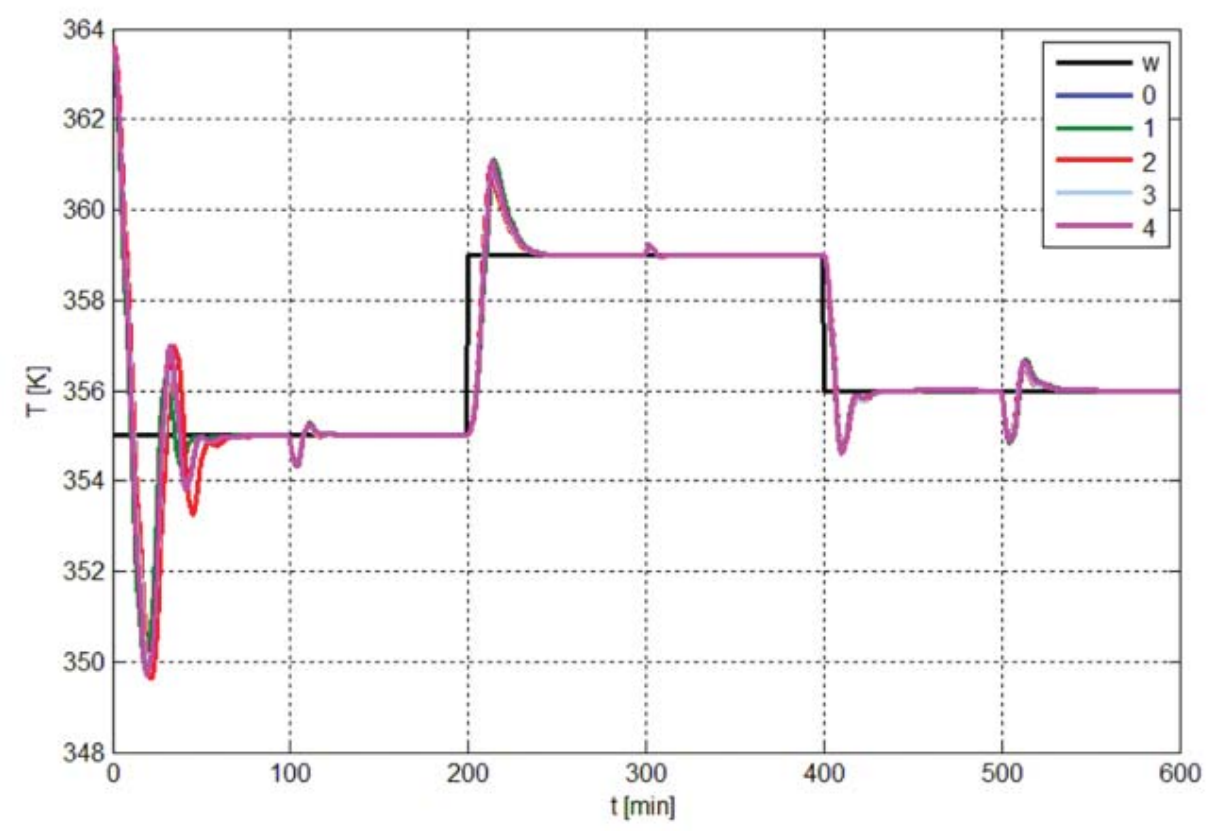

Fig. 3. Small-gain control of the CSTR - the reacting mixture temperature: 0 - nominal system, 1, 2, 3, 4-vertex systems. 


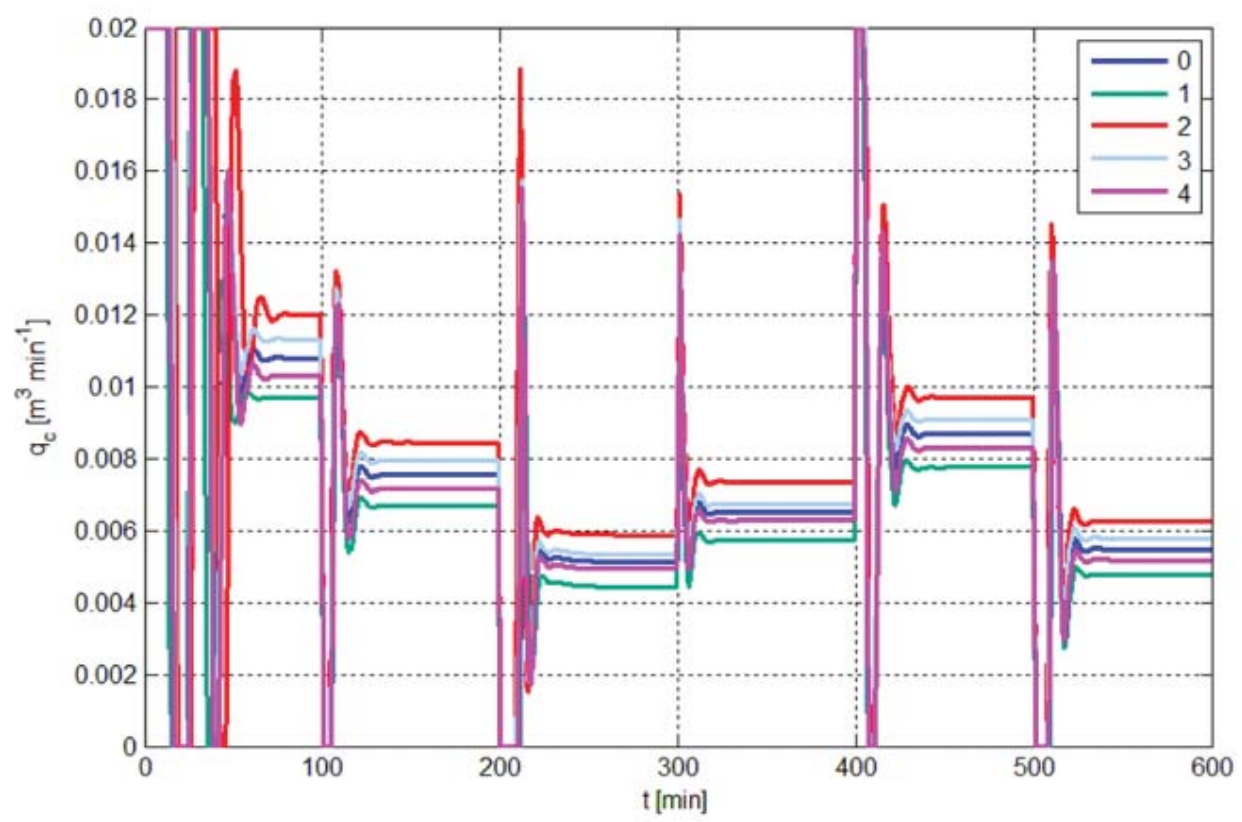

Fig. 4. Small-gain control of the CSTR - the coolant flow rate: 0 - nominal system, 1, 2, 3, 4- vertex systems.

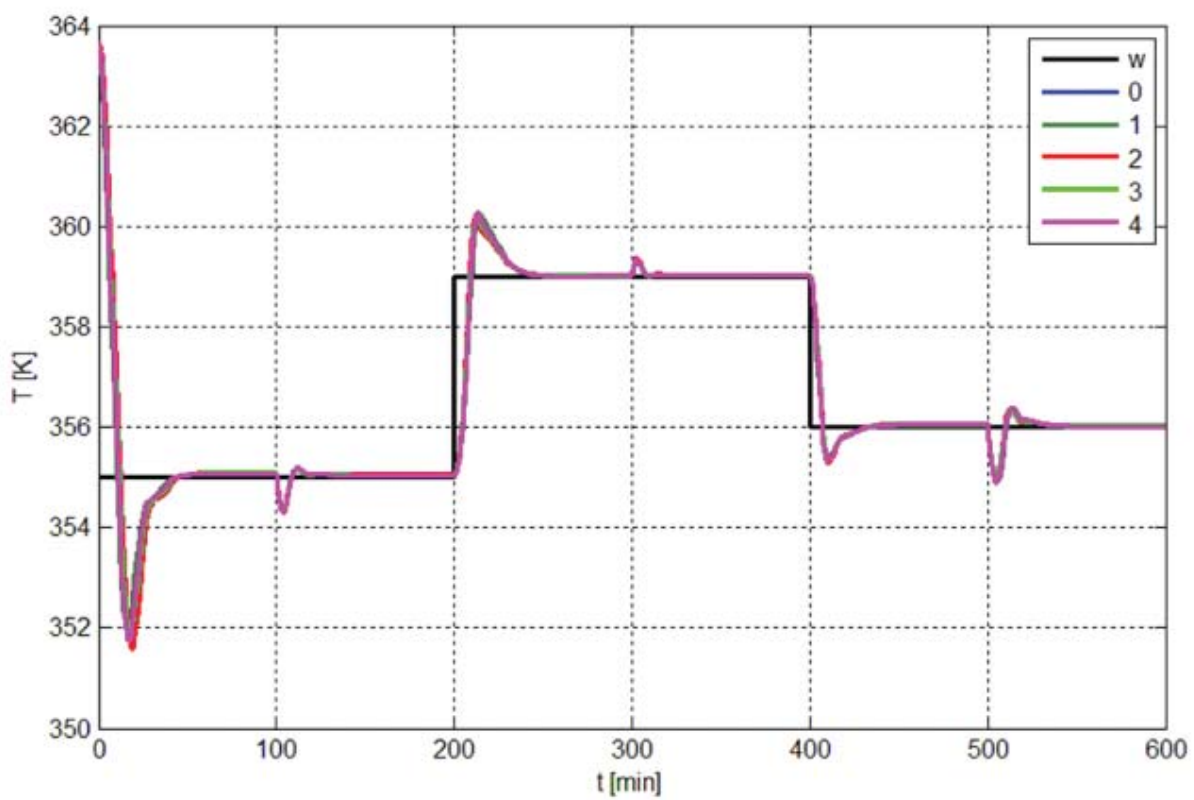

Fig. 5. $H_{2} / H_{\infty}$-control of the CSTR - the reacting mixture temperature: 0 - nominal system, 1, 2, 3, 4 - vertex systems.

nominal and all vertex systems. Figure 6 presents the simulation results for the control signal.

The comparison of the proposed controllers was made using IAE and ISE integral performance indexes described as follows:

$$
I A E=\int_{0}^{\infty}|e| \mathrm{d} t, I S E=\int_{0}^{\infty} e^{2} \mathrm{~d} t
$$

The IAE and ISE values are given in Table 3. Smaller_IAE and $I S E$ values were obtained using $H_{2} / H_{\infty}$-controller. The lower IAE and ISE values were achieved by increasing of the $r$ value.
Tab. 3. Comparison of the simulation results by $I A E$ and ISE.

\begin{tabular}{lcccc}
\hline \multirow{2}{*}{ control } & \multicolumn{2}{c}{ small-gain control } & \multicolumn{2}{c}{$\boldsymbol{H}_{2} / \boldsymbol{H}_{\infty}$-controller } \\
\cline { 2 - 5 } & $\boldsymbol{I A E}$ & $\boldsymbol{I S E}$ & $\boldsymbol{I A E}$ & $\boldsymbol{I S E}$ \\
\hline nominal system & 218 & 764 & 186 & 577 \\
vertex system 1 & 208 & 707 & 178 & 532 \\
vertex system 2 & 234 & 848 & 199 & 638 \\
vertex system 3 & 215 & 752 & 190 & 584 \\
vertex system 4 & 224 & 785 & 186 & 576 \\
\hline
\end{tabular}




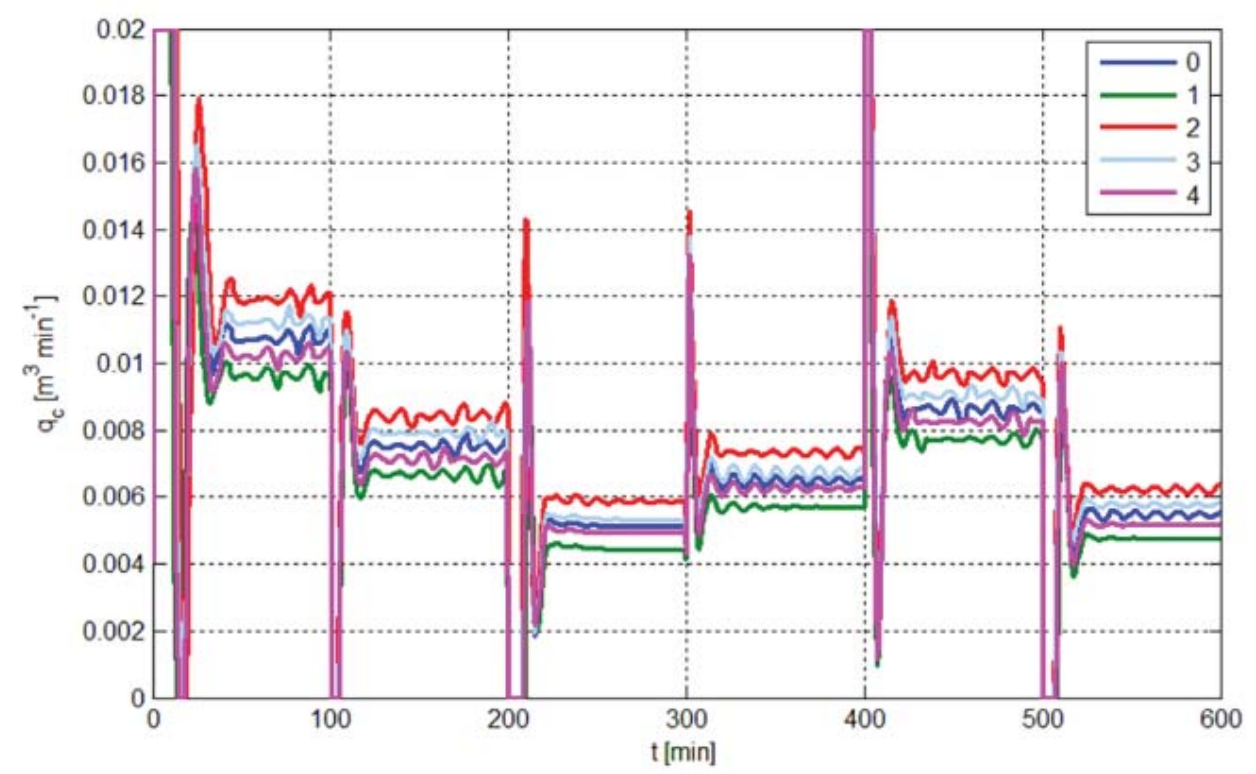

Fig. 6. $H_{2} / H_{\infty}$-control of the CSTR - the coolant flow rate:

0 - nominal system, $1,2,3,4-$ vertex systems.

\section{Conclusions}

The robust controllers have been applied to the control of the exothermic CSTR with uncertain parameters. The controllers were designed using the small gain theorem and the $H_{2} / H_{\infty}$ control techniques. Simulations confirmed that designed controllers can be successfully used for control of CSTRs with uncertainties and disturbances, even though the CSTRs are very complicated systems from the control point of view. All simulations were done using MATLAB. Simulation results obtained using designed controllers were compared using integral quality criteria IAE and ISE. The presented results provide satisfactory control responses for the set-point tracking as well as for the step load disturbance attenuation. The achieved simulation results confirm that the small-gain control and the $H_{2} / H_{\infty}$ control are some of the possibilities for successful control of the chemical reactor.

\section{Acknowledgments}

The authors gratefully acknowledge the contribution of the Scientific Grant Agency of the Slovak Republic under the grants 1/0973/12.

\section{References}

Angeli D and Astolfi A (2007) A tight small-gain theorem for not necessarily ISS systems, Syst. Control Lett. 56(1): 87-91.

Antonelli R, Astolfi A (2003) Continuous Stirred Tank Reactors: Easy to Stabilise? Automatica 39(10): 817-1827.
Bequette BW (1991) Nonlinear control of chemical processes: a review. Industrial Engineering Chemical Research 30: 1391-1413.

Bosgra OH, Kwakernaak H, Meinsma G (2000) Design methods for control systems, DISC lecture notes 20002001, http://web.boun.edu.tr/eskinat/ME687.html, accessed 18. 3. 2013.

Doyle JC, Stein G (1981) Multivariable Feedback Design - Concepts for a Classical Modern Synthesis. IEEE Transactions on Automatic Control 26: 4-16.

Doyle JC (1984) Lecture Notes, ONR/Honeywell Workshop on Advances in Multivariable Control, Minneapolis.

Gerhard J, Monningmann M, Marquardt W (2004). Robust stable nonlinear control and design of a CSTR in a large operating range. In Proceedings of the $7^{\text {th }}$ International Symposium on Dynamics and Control of Process Systems. Massachusetts. IFAC. 92.

Green M and Limebeer DNJ (1994) Linear robust control. Prentice Hall. New Jersey.

Henrion D, Tarbouriech S, Kučera V (2005) Control of linear systems subject to time-domain constraints with polynomial pole placement and LMIs, IEEE Transactions on Automatic Control 50(9), 1360-1364.

Chaves M (2005) Input-to-state stability of rate-controlled biochemical networks, SIAM Journal on Control and Optimization 44(2): 704-727.

Chilali $\mathrm{M}$ and Gahinet $\mathrm{P}$ (1996) $\mathrm{H}_{\infty}$ design with pole placement constraints: An LMI approach. IEEE Trans. Automat. Contr. 41(3): 358-367.

Ingham J, Dunn IJ, Heinzle E, Přenosil JE (1994) Chemical Engineering Dynamics. VCH Verlags-gesellschaft. Weinheim.

Ito $\mathrm{H}$ (2008) A degree of flexibility in Lyapunov inequalities for establishing input-to-state stability of interconnected systems, Automatica 44(9): 2340-2346.

Jiang ZP, Mareels IMY and Wang Y (1996) A Lyapunov formulation of the nonlinear small-gain theorem 
for interconnected ISS systems, Automatica 32(8): $1211-1215$

Karafyllis I and Zhong-Ping J (2007) A small-gain theorem for a wide class of feedback systems with control application. SIAM Journal on Control and Optimization 46(4): 1483-1517.

Khalil HK (1996) Nonlinear systems. Prentice Hall. New Jersey.

Kučera V (2007) Polynomial control: Past, present and future. In Proc. $16^{\text {th }}$ International Conference Process Control, Štrbské Pleso 2007, 1-23.

Kučera V (2008) A comparison of approaches to solving the $H_{2}$ control problem. Kybernetika 44(3), 328-335, ISSN 0023-5954.

Kwakernaak H (2002) Mixed sensitivity design. In: $15^{\text {th }}$ IFAC World Congress, Barcelona, Spain.

Laila DS and Nešić D (2003) Discrete-time Lyapunovbased small-gain theorem for parameterized interconnected ISS systems, IEEE Trans. Autom. Control 48(10): 1783-1788.

Luyben WL (2007) Chemical reactor design and control. John Wiley \& Sons. New Jersy. ISBN 978-0-470-09770-0.

Molnár A, Markoš J, Jelemenský L' (2002) Accuracy of Mathematical Model with Regard to Safety Analysis of Chemical Reactors. Chemical Papers 56: 357-361.

Nešić D and Liberzon D (2005) A small-gain approach to stability analysis of hybrid systems, in Proc. 44th IEEE Conf. on Decision and Control Available: http:// decision.csl.uiuc.edu/ ${ }^{\sim}$ liberzon/publications.html.

Scherer CW (2006) LMI relaxations in robust control, European Journal of Control 12: 3-29, DOI: 10.3166/ ejc.12.3-29.
Scherer C, Gahinet P, Chilali M (1997) Multi-objective output-feedback control via LMI optimization. IEEE Trans. Automat. Contr. 42: 896-911.

Sontag ED (1989) Smooth Stabilization Implies Coprime Factorization, IEEE Transactions on Automatic Control 34: 435-442.

Teel AR (2005) Input-to-State Stability and the Nonlinear Small Gain Theorem, Preprint.

Tlacuahuac AF, Alvarez J, Guerra ES, Oaxaca G (2005) Optimal Transition and Robust Control Design for Exothermic Continuous Reactors. AIChE Journal 51(3): 895-908.

Vasičkaninová A, Bakošová M (2009) Neural Network Predictive Control of a Chemical Reactor. Acta Chimica Slovaca 2(2): 21-36.

Vasičkaninová A， Bakošová M，Karšaiová M (2011) Neuro-fuzzy Control of a Chemical Reactor with Uncertainties. Ed: Fikar M, Kvasnica M, In Proceedings of the $18^{\text {th }}$ International Conference on Process Control, 360-365, Slovak University of Technology in Bratislava, Tatranská Lomnica, Slovakia.

Veselý V and Harsányi L (2007) Robust control for dynamic systems (in Slovak). STU, Bratislava.

Yang F, Gani M, Henrion D (2007), Fixed-order robust $\mathrm{H}_{\infty}$ controller design with regional pole assignment, IEEE Transactions on Automatic Control, 52: 1959-1963, DOI: 10.1109/TAC.2007.90624.

Zames G, Francis BA (1983). Feedback, Minimax Sensitivity and Optimal Robustness. IEEE Transactions on Automatic Control. 28: 586-601. 